\section{Journey to the centre of the Earth}

\section{Don L. Anderson}

The Earth's Core, 2nd Edn. By J.A. Jacobs. Academic:1987. Pp.416. £40, \$65.

THE study of the Earth's core might seem to be as academic as the study of a black hole or a pulsar. If it were not for the core, however, compasses would not work, we wouldn't know about plate tectonics and we probably wouldn't even have evolved to worry about such things. The core is a sloshing ball of molten metal, half the radius of the Earth, in which is suspended a sphere of solid iron. It is the source of the magnetic field which shields us from harmful emissions from outer space. The liquid outer core and solid inner core reveal their secrets through their effects on seismic waves, the magnetic field and the motions of the Earth.

This second edition of Jacobs's book, first published in 1975, comes at a time of rapidly expanding interest in the core and information about it. It therefore serves as an update, or starting point, for a rapidly moving field rather than as the final word. The author manages in about 400 pages painlessly to cover much of the ground expected in an introductory survey course. The core turns out to be an exciting place.

The 'facts' concerning seismology,

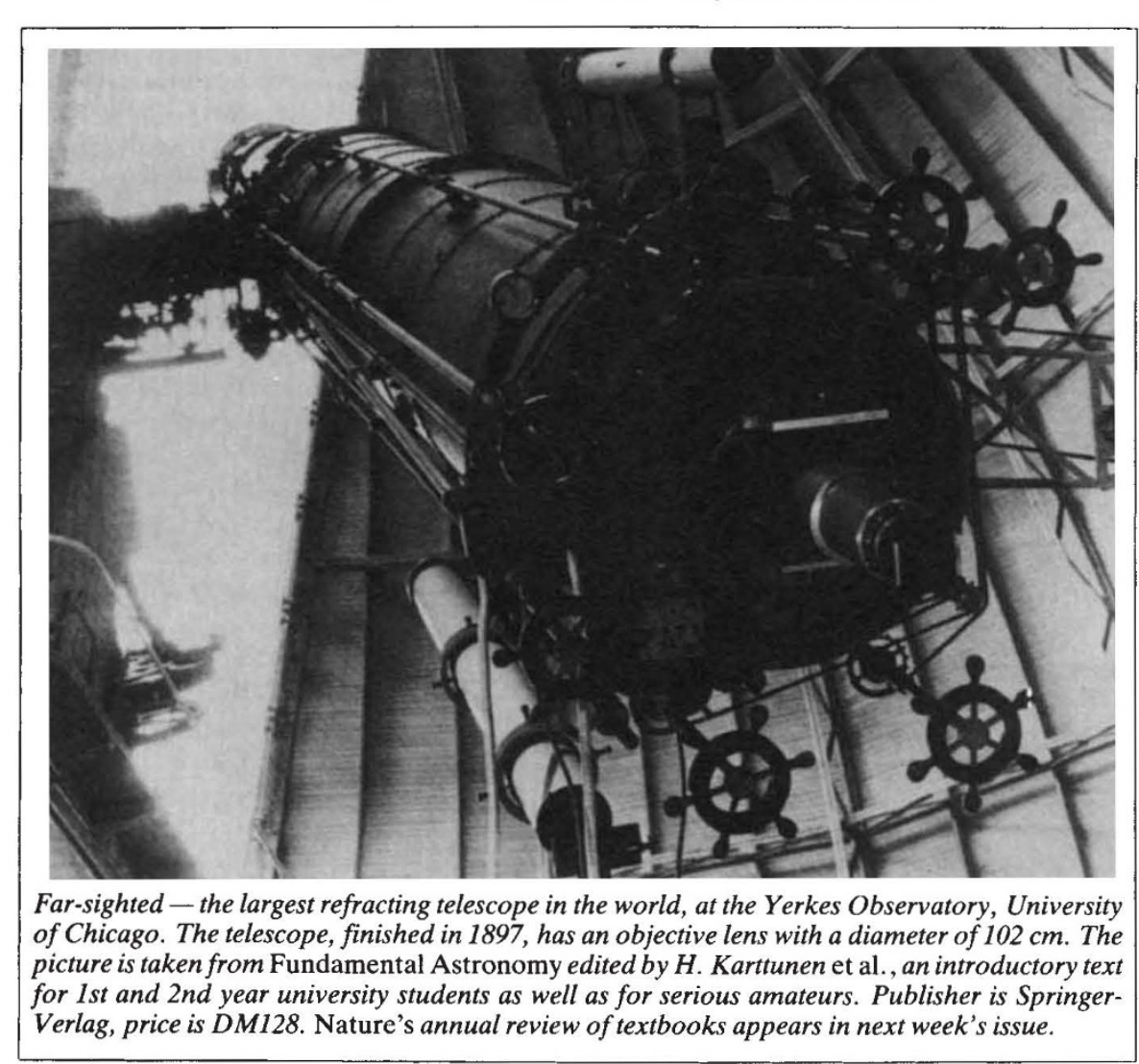

Far-sighted - the largest refracting telescope in the world, at the Yerkes Observatory, University of Chicago. The telescope, finished in 1897, has an objective lens with a diameter of $102 \mathrm{~cm}$. The picture is taken from Fundamental Astronomy edited by $H$. Karttunen et al., an introductory text for 1st and 2nd year university students as well as for serious amateurs. Publisher is SpringerVerlag, price is DM128. Nature's annual review of textbooks appears in next week's issue.

geomagnetism, palaeomagnetism, Earth rotation and high-pressure laboratories are remarkably up to date and are sprinkled throughout the book as befits their diversity. The core cannot be studied in isolation and particular attention is paid to the core-mantle boundary and $\mathrm{D}^{\prime \prime}$, the layer at the base of the mantle. Jacobs wisely uses Chapter 1 to describe the general physical properties of the Earth and writes an admirable introduction to the physics of the Earth's interior, including the core. He then describes the various theories and constraints on the origin and thermal regime of the core.

The reader who has never worried much about the core will be surprised that some 500 papers are mentioned in the first three chapters. Another 300 are drawn upon in the longest chapter, which covers the Earth's magnetic field. Other chapters treat the constitution of the core and the cores of other planets, and have their own extensive bibliographies. The large number of up-to-date references covering all aspects of the subject and related studies is an important feature of the book.

Jacobs has done an exceptional job of pulling together a huge amount of information and making it both interesting and understandable. Although the book is about the core, it is also a good place to learn about planetary interiors and how geophysics is done.

Don L. Anderson is Professor of Geophysics and Director of the Seismological Laboratory at the California Institute of Technology, Pasathe California Institute of T

\section{Evolving editions}

\author{
Joseph G. Gall
}

Molecular Biology of the Gene, 4th Edn. Vols I and II. By James D. Watson, Nancy H. Hopkins, Jeffrey W. Roberts, Joan Argetsinger Steitz and Alan M. Weiner. Benjamin/Cummings: 1987. Pp.1,189. Vol. I \$39.95, £21.95. Vol. II $\$ 29.95, £ 21.95$.

JIM Watson's Molecular Biology of the Gene was first published in 1965 . The book brought together for the first time the new prokaryotic genetics and the new biochemistry of nucleic acids and proteins, and it was enormously popular. The success of the first edition was a tribute to Watson's intellectual synthesis, helped greatly by his direct and lively presentation and the skilful use of Scientific American style diagrams and figures. The second and third editions of 1970 and 1976 required enlargement to accommodate much additional information, but they were completed before the revolution in recombinant DNA technology and DNA sequencing.

The fourth edition comes when every aspect of cell and molecular biology has been touched by these methods and as fresh information pours in at an everincreasing rate. There are now five authors instead of one, the overall number of pages has more than doubled, and there are two volumes. The 28 chapters are wide-ranging, including not only the traditional subject matter of prokaryotic molecular biology, but extensive discussions about eukaryotic cells and multicellular organisms.

The first volume covers the general principles underlying gene structure and function in both prokaryotes and eukaryotes, and is intended to stand alone as the text for a beginner's course in molecular biology at the university level. Only the first few chapters, which deal with the elements of genetics and biochemistry, are recognizable from the previous edition; the rest are new or have been completely rewritten by Jeffrey Roberts and Joan Steitz. The second volume is much smaller, although in the preface we are promised that it will be expanded in subsequent editions. Written primarily by Nancy Hopkins and Alan Weiner, it concentrates on cellular differentiation and development, eukaryotic viruses, cancer and the origins of life.

This is an extraordinarily well-done project, clearly and concisely written, pleasing to the eye, and full of basic information on an incredible array of topics. A glance over the chapters shows how far we have come in understanding the molecular structure of genes and the processes they control - in every respect 